\title{
Elastomer Karakterli Kauçuk Burçlar İçin Otomatik Test Kontrol Ünitesi Geliştirilmesi ve SCADA ile İzlenmesi
}

\author{
Selim Sefa Baysal ${ }^{1 *}$, Muhammed Abdullah Özel ${ }^{2}$, Mehmet Can Küçükbaşak ${ }^{3}$, Furkan Göğer ${ }^{4}$, Cemil Sungur \\ ${ }^{1 *}$ Aydınlar Yedek Parça San. Ve Tic. A.Ş., Konya, Türkiye (ORCID: 0000-0002-7439-4087), baysal.selimsefa@aydtr.com \\ 2 Aydınlar Yedek Parça San. Ve Tic. A.Ş., Konya, Türkiye (ORCID: 0000-0003-3056-6438), ozel.muhammed@aydtr.com \\ ${ }^{3}$ Aydınlar Yedek Parça San. Ve Tic. A.Ş., Konya, Türkiye (ORCID: 0000-0001-6339-3444), kucukbasak.mehmetcan@aydtr.com \\ ${ }^{4}$ Aydınlar Yedek Parça San. Ve Tic. A.S.., Konya, Türkiye (ORCID: 0000-0002-7843-2757), goger.furkan@aydtr.com \\ ${ }^{5}$ Konya Teknik Üniversitesi, Elektrik-Elektronik mühendisliği Bölümü, Konya, Türkiye (ORCID: 0000-0003-2340-6225), csungur@ktun.edu.tr
}

(2nd International Conference on Computer, Electrical and Electronic Sciences ICCEES 2021, September 1-3, 2021)

(DOI: 10.31590/ejosat.1005056)

ATIF/REFERENCE: Baysal, S., Ozel, M., Kucukbasak, M., Goger, F. \& Sungur, C. (2021). Elastomer Karakterli Kauçuk Burçlar İçin Otomatik Test Kontrol Ünitesi Geliştirilmesi ve SCADA ile İzlenmesi. Avrupa Bilim ve Teknoloji Dergisi, (30), 66-68.

$\ddot{\mathbf{O} z}$

Elastomer karakterli kauçuk burçlar, araç parçalarının bağlantı noktaları arasında kuvveti iletebilmek, titreşimleri sönümlemek ve parçalar arası boşluğu giderebilmek amacıyla kullanılmaktadır. Burçların çok yönlü kuvvetlere ve burulmalara maruz kaldığı bilinmektedir. Bu nedenle burçlarda kauçuğun metale iyi yapışmış olması ve burçta kullanılan kauçuğun istenilen sertlikte olması en önemli özelliklerdir. Bu özelliklerin doğruluğu burca uygulanan statik testler ile sağlanmaktadır. Burca uygulanan statik test yükleri test edilen burcun yapısına göre belirlenmektedir. Bu çalışma ile burçlarda deformasyon olup olmadı̆̆ı, yapışma problemi, standart yükler altında burçların esneme değerlerinin ölçülmesi ve doğrulanması amaçlanmıştır. Burç üzerine uygulanacak olan yükler, test kontrol ünitesine tanımlanmış, sensörlerden toplanan veriler yapay sinir ağlarına aktarılarak veri tabanı oluşturulmuştur. Oluşturulan veri tabanı, her bir burç için toplanan deformasyon ve yapışma verilerini kendi içerisinde karşılaştırmıştır. Karşılaştırma sonucunda deformasyon, kauçuk yapışma oranı önceki veriler ile kıyaslandığında burcun kopma değişimi \%15 ve üzeri olduğunda test sistemi otomatik olarak durarak burcun gövdeden kopmasını engellemiştir.

Anahtar Kelimeler: Burç, Test Kontrol, Kauçuk, Yapay Zekâ, Deformasyon.

\section{Development of an Automatic Test Controller for Rubber Bushings with Elastomer Character and Monitoring with SCADA}

\begin{abstract}
Rubber bushings with elastomer characters are used to transmit force between the connection points of the vehicle parts, absorb vibrations and remove the clearances between parts. It is known the rubber bushings be exposed to versatile forces and torsions. Because of this most important proberties of rubber bushings are adhesion on metal housing and rubbers stiffness that used on bushing. To test adhesion and stiffness some static tests performed to rubber bushing. The force that performed on static test is determined by rubber bushings characteristics. In this study, it is aimed to control the deformation and adhesion problem and verify the stiffness values of the bushings under standard loads. The loads to be applied on the bushing are defined in the test control unit, and data collected from the sensors are transferred to artificial neural networks and a database is created. The created database compared the deformation and adhesion data collected for each bush within itself. As a result of the comparison, the test system stopped automatically when the deformation and rubber adhesion rate of the bush is $15 \%$ or more compared to the previous data, preventing the bush from breaking off from the body.
\end{abstract}

Keywords: Bushing, Test Control, Rubber, Artificial Intelligent, Deformation.

\footnotetext{
*Sorumlu Yazar: baysal.selimsefa@aydtr.com
} 


\section{Giriş}

Burçlar iç ve diş borunun arasında vulkanizasyon yöntemi ile elastomer malzeme yapıştırılmış olan süspansiyon sistemi parçasıdır. Burçlar otomotivde süspansiyon sistemi bileşenlerinde salıncak ve rotilli denge kollarında bulunur. Burçlar, üzerine gelen yükleri, araç altı titreşimleri ve şokları elastomer malzeme sayesinde en aza indirerek yükler, şoklar ve titreşimleri diğer bağlantı parçalarına iletir [1].

Burç seçimi yaparken en önemli parametre kesme modülüdür. Kesme modülü ise kauçuk sertliği, elastite modülü, $\mathrm{k}$ şekil değiştirme faktörü gibi etkenlere bağlıdır. K şekil değiştirme faktörü uygulanan strese göre değişkenlik gösterip buda doğrusal olmayan bir kuvvet-yer değiştirme eğrisine yol açar. Burçlar tasarımına göre eksenel ve radyal yönde 1 ile $3 \mathrm{~mm}$ arasında deplasman olacak şekilde tasarlanır [6].

Otomotivde kullanılan burç genellikle eksenel, radyal, torsiyonel, eğilme, radyal torsiyonelin aynı anda olduğu ve eksenel ile torsiyonun aynı olduğu yük ve hareketlere maruz kalır ([1], [2]).

Burçlar, araçlarda yol düzensizliklerinden kaynaklanan titreşimleri ortadan kaldırmak, eksenlerin küçük yanlış hizalanmasına izin vermek, şanzımandan gelen gürültüyü azaltmak veya mekanik aksamın aşınmasını azaltmak için kullanılır. Burçlar, genellikle enerji dağıtımında kullanılan özel bir kauçuktan yapılmıştır. Kuvvetler ve momentler ile bunların karşılık gelen yer değiştirmeleri ve dönüşleri arasında doğrusal olmayan bir viskoelastik ilişki sunar.

$\mathrm{Bu}$ statik ve dinamik yüklemeler sonucunda burçda deformasyonlar oluşmaktadır. $\mathrm{Bu}$ yüzden üretim sonrasında üretilen burçlara testler yapılmaktadır. $\mathrm{Bu}$ testler sonucunda burçda olabilecek deformasyonlar ve burcun tepkilerine, kuvvet yer değiştirme verilerine bakılmaktadır. Üretim sonrasında yapılan dinamik testler ile kauçuğun yapışma problemleri ve kauçuk yırtılma ömürleri incelenir. Statik testler ile birlikte ise kuvvet yer değiştirme eğrileri incelenir. [7].

Mevcut sistemlerde kullanılan statik test makineleri tamamen manuel bir denetiminde kontrol edilmektedir. Literatür taramalarında burçların mekanik özelliklerini geliştirmeye yönelik ya da statik ve dinamik testde burç davranışlarını inceleyen çalışmalar mevcutken statik test makinelerinin kontrolünü kolaylaştırmaya yönelik bir çalışmaya rastlanmamıştır. $\mathrm{Bu}$ çalışmada bundan dolayı bir test kontrol ünitesi geliştirilmesi amaçlanmıştır. Test kontrol ünitesi burcun tabladaki aparatta var yok durumunu denetler. Ĕger burç var ise kauçuğa standart yük uygulanmaya başlanır. Burcun esnemesi lineer cetvel ve lazer mesafe sensöründen alınan test başlangıcı ve test sonu alınan veriler ile hesaplanır. Burca standart yük uygulandıktan sonra, kameralar yardımı ile görüntüler alınıp bu görüntüler yapay sinir ağları yardımı ile kontrol edilir üretimsel hata olabilecek yük altında burçtaki yapışma problemleri veya hatalı yapılması sonucu burçtaki yırtılmalar denetlenir.

Loadcell ile algılanan ani yük düşmeleride kontrol edilip ileri seviyedeki yırtılma ve yapışma problemlerinde kauçuğun iç ve dış borulardan kopması veya ayrılması engellenir.

\section{Materyal ve Metot}

\subsection{Test Yöntemi ve Testin Uygulanması}

Burçların yapışma problemlerinin olup olmadığını anlamanın yollarından birisi, burcun dış borusundan sabitlenip iç borusuna eksenel yönde belirli bir yük uygulayarak göz ile kontrol edilmesidir.

$\mathrm{Bu}$ yol ile tespit sırasında yük ve mesafe kontrollü bir cihaz gerekir. $\mathrm{Bu}$ özelliklere uygun olarak tasarlanan burç test cihazımızda testin uygulanması Şekil 1'deki görsel ile örneklendirilmiştir. Burç cihazdaki piston tarafından eksenel yönde yük uygulanacak şekilde diş borusundan sabitlenmiştir Piston direkt olarak burcun iç borusuna belirlenen yükü uygular ve burçtaki yapışma sorununun kontrolü için 2 sn yük konumunda kalır. Test cihazı üzerinde bulunan yük hücresi ile ne kadar yük uygulandığını ölçerken aynı zamanda piston üzerinde bulunan lineer cetvel ve lazer mesafe ölçüm sensörünün beraber çalışması ile mesafe ölçümü de yapmaktadır.

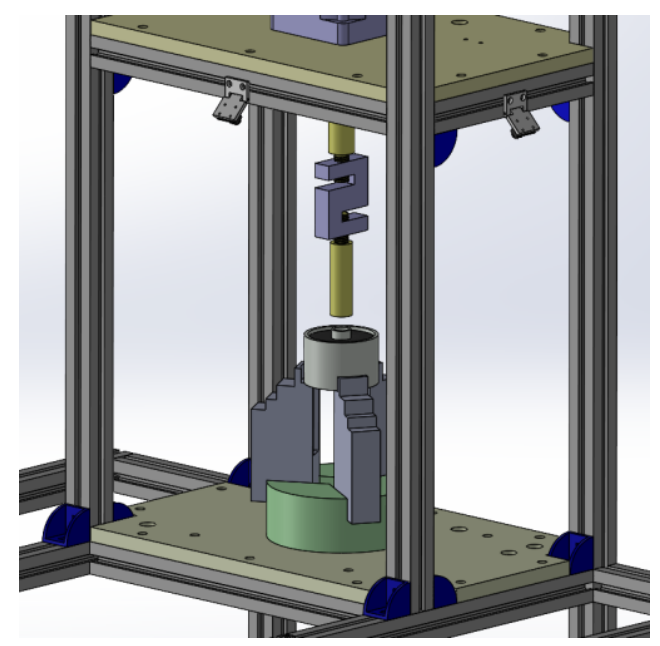

Şekil 1. Test Cihazı Burç Yerleşimi

Test cihazının kontrolü SCADA üzerinden kontrol edilir. Şekil 2'de gösterilen SCADA ekranı üzerinden "STATIKK TESTLER" sekmesine girilerek basma testi seçilir. Şekil 3'de gösterilen bu ekran üzerinden burç çeşidi ve kauçuk sertliğine göre ne kadar yük uygulanacağı girilen değerler ile belirlenir. SCADA üzerinden cihazda bulunan yük hücresi, lineer cetvel ve lazer mesafe ölçüm sensörlerinin değerleri gösterilmektedir. Test cihazı sensörlerden gelen veriler üzerine burçta kopma veya yırtılma olması durumunu gözetler ve bu durumda testi durdurur.

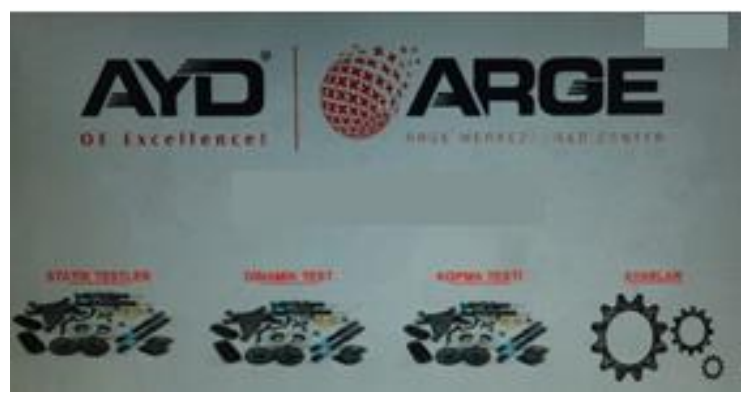

Şekil 2. Test Cihazı SCADA Ekranı

Burç kontrol test cihazında seri üretimden gelen bir tip ürünün tüm numuneleri kontrol edilir. Seri imalatta üretilen ürünün \%100 kontrolü yapıldığı sırada SCADA üzerinden kontrolü yapılan ürünlerin kontrol yüküne ulaştığı noktadaki yük verisi ve mesafe 
verileri hem lineer cetvel hem de lazer mesafe ölçüm sensörü ile alınarak SCADA üzerindeki veritabanına eklenir. Veritabanına eklenmesi gereken veriler ürünün kontrolü onaylanırsa veritabanına eklenir.

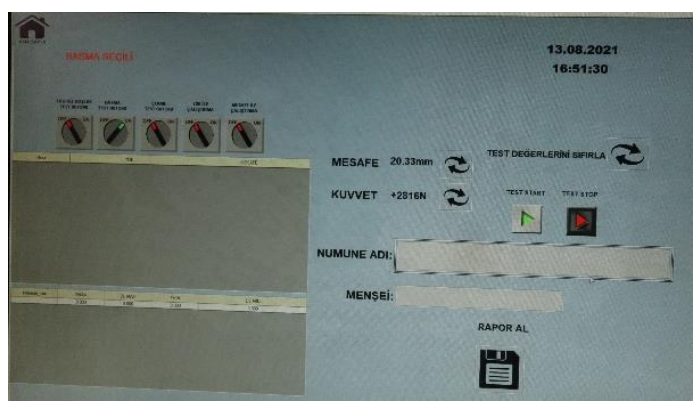

Şekil 3. Test Cihazı SCADA Veri Giriş Ekranı

Ürünün test cihazında kontrolü yapılırken alınan veriler, aynı ürünün bir sonraki numunesi test edilirken kullanılır. Her kontrolü yapılan ürünün verileri, veritabanına eklendiği için, kontrol testi yapılan numune sayısı arttıkça veritabanında bulunan veri sayısı artar. Bu durumda veri hassasiyeti artar ve numune sayısı arttıkça doğruluk \%100 noktasına giderek yaklaşır.

Veritabanındaki veriler, numune test edilirken ulaşması gereken yüke önceki numunelerin ulaştığı mesafe değerinden $\pm \% 15$ fark ile ulaşması durumunda ürünün görünmeyen kısımlarında olan bir problem sebebi ile "Ürün Hatalı" uyarısı vererek kontrol işlemini durdurur ve ürün hatalı olarak ayrılır.

\subsubsection{Algılama ve Karar Mekanizmast}

Test edilen burçta problemlerin tespiti kameralar ile alınan görüntülerin işlenmesi ile tespit edilir. Tespit işlemi evrişimli sinir ağı olan CNN derin öğrenme algoritması ile yapılmaktadır. CNN, çoklu yapay nöron katmanlarından oluşur. Görüntü girdisi evrişimli sinir ağına verildikten sonra görüntüyü küçük nesnelere ayırarak oluşan deformasyonları tespit eder. Test cihazı üzerine yerleştirilen burca yükü uyguladığı ve yük posizyonunda 2 sn bekleme süresinde cihaz üzerinde bulunan dört adet dijital kamera tarafından görseller alınır. Alınan görseller SCADA üzerinde yansıtılır. Yansıltılma sonucunda herhangi bir sorun tespiti halinde SCADA üzerinde uyarı ve sorunun olduğu nokta belirtilir.

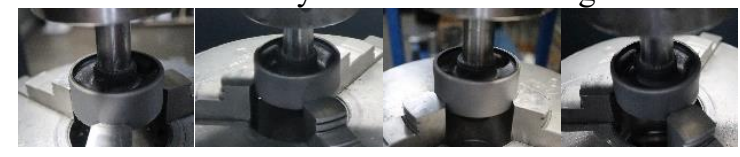

Şekil 4. Kameralardan alınan görüntü örnekleri

\section{Araştırma Sonuçları ve Tartışma}

$\mathrm{Bu}$ çalışma ile test cihazının yarı-otomatik kullanım ve tam otomatik kontrollü olması, test edilen parçanın test süresinin ve kontrol süresinin kısalmasını sağlamıștır. Kontrol süresinin kısalması, tam otomatik görüntü işleme kontrol mekanizması ile gerçekleştirilmiş ve bu kontrol mekanizması ile birlikte, test edilen parçanın kontrolünün göz ile yapılmasına gerek kalmamıştır. Bu sebeble kontroldeki hata payı azalmıştır. Burç deformasyon problemlerinde karar yapısı geliştirilmiştir. Aynı zamanda veritabanına alınan yük ve mesafe verilerinin kontrolü ile göz ile tespiti yapılamayacak hataların ortaya çıkarılması ve böylelikle hatalı ürünün kullanımı önlenmiştir.

\section{Sonuç}

Yapılan çalışma ile süspansiyon bileşeninin önemli parçalarından olan burçlarda, esneme testi sırasında oluşan deformasyon, yapışma gibi problemler incelenmiştir. İnceleme neticesinde uygulanan yük sonrası sensörlerden alınan veriler ile, burç üzerinden alınan görüntüler $\mathrm{CNN}$ evrişimli ağlarda derin öğrenme algoritmaları ile tespit edilerek \%100 kontrol sağlanmıştır. Otomatik test sistemi ile test yapılacak burçlarda oluşabilecek yırtılmaları kontrol etmede manuel sisteme göre \%90 oranda doğruluk tespit edilmiştir.

\section{Kaynakça}

Kadlowec, J., Wineman, A. \& Hulbert, G, (2003). Elastomer bushing response: experiments and finite element modeling. Acta Mechanica 163, 25-38.

Adkins, J \& Gent, A., (2002). Load-deflexion relations of rubber bush mountings. British Journal of Applied Physics. 5. 354.

Ok, J., Yoo, W., \& Sohn, J., (2007). Experimental study on the bushing characteristics under several excitation inputs for bushing modeling. International Journal of Automotive Technology, 8, 455-465.

García Tárrago, M. J., Kari, L., Viñolas, J., \& Gil-Negrete, N., (2007). Torsion stiffness of a rubber bushing: A simple engineering design formula including the amplitude dependence. The Journal of Strain Analysis for Engineering Design, 42(1), 13-21.

Yoo, W. S., Baek, W. K., \& Sohn, J. H., (2004). A practical model for bushing components for vehicle dynamic analysis. International journal of vehicle design, 36(4), 345-364.

Heissing, B., (2011). Chassis handbook: fundamentals, driving dynamics, components, mechatronics, perspectives, (M. Ersoy, Ed), Vieweg + Teubner, 316-320.

Kuo, E., (1997)."Testing and Characterization of Elastomeric Bushings for Large Deflection Behavior," SAE Technical Paper 970099.

H. S. Lee J. K. Shin S. Msolli H. S. Kim (2015) Department of Mechanical, Robotics and Energy Engineering, Dongguk University-Seoul, 30 Pildong-ro 1-gil, Jung-gu, Seoul 04620

G. Previati, M. Kaliske, M. Gobbi, and G. Mastinu, (2011). "Structural optimization of a rubber bushing for automotive suspension," in Proceedings of the 7th European Conference on Constitutive Models for Rubber, ECCMR VII, pp. $307-$ 312, Dublin, Ireland,

K. Hasanpour, S. Ziaei-Rad, and M. Mahzoon, (2009). "A large deformation framework for compressible viscoelastic materials: Constitutive equations and finite element implementation," International Journal of Plasticity, vol. 25, no. 6 , pp. 1154- 1176 .

W. Wei, A. Liu, A. Liu, S. C.-Y. Lu, and T. Wuest, (2015). "Product requirement modeling and optimization method based on product configuration design," Procedia CIRP, vol. 36 , pp. 1-5. 